\title{
Balanced polymorphisms and their divergence in a Heliconius butterfly
}

\author{
James Ogilvie ${ }^{1}$, Steven Van Belleghem ${ }^{2}$, Mathieu Chouteau ${ }^{3}$, Ryan Range ${ }^{1}$, Riccardo \\ Papa $^{2}$, Owen McMillan ${ }^{4}$, and Brian Counterman ${ }^{1}$ \\ ${ }^{1}$ Auburn University \\ ${ }^{2}$ University of Puerto Rico Rio Piedras \\ ${ }^{3}$ Universite de la Guyane \\ ${ }^{4}$ Smithsonian Tropical Research Institute
}

September 24, 2021

\begin{abstract}
The evolution of mimicry in similarly defended prey is well described by Müllerian mimicry theory, which predicts the convergence of warning patterns in order to gain the most protection from predators. However, despite this prediction, we can find great diversity of color patterns amongst Müllerian mimics such as Heliconius butterflies in the neotropics. Furthermore, some species have evolved the ability to maintain multiple distinct warning patterns in single populations, a phenomenon known as polymorphic mimicry. The adaptive benefit of these polymorphisms is questionable since variation from the most common warning patterns is expected to be disadvantageous as novel signals are punished by predators naive to them. In this study, we use artificial butterfly models throughout Central and South America to characterize the selective pressures maintaining polymorphic mimicry in Heliconius doris. Our results highlight the complexity of positive frequency-dependent selection, the principal selective pressure driving convergence amongst Müllerian mimics, and its impacts on interspecific variation of mimetic warning colouration. We further show how this selection regime can both limit and facilitate the diversification of mimetic traits.
\end{abstract}

Balanced polymorphisms and their divergence in a Heliconiusbutterfly

Ogilvie, G. James ${ }^{1,3}$ * (orcid ID: 0000-0003-2487-7336)

Van Belleghem, Steven² (orcid ID: 0000-0001-9399-1007)

Range, Ryan ${ }^{1}$ (orcid ID: 0000-0002-6619-3453)

Papa, Riccardo ${ }^{2}$ (orcid ID: 0000-0002-7986-9993)

McMillan, W. Owen ${ }^{3}$ (orcid ID: 0000-0003-2805-2745)

Chouteau, Mathieu ${ }^{4}$ (orcid ID: 0000-0003-2043-0895)

Counterman, A. Brian ${ }^{1}$ (orcid ID: 0000-0003-2724-071X)

${ }^{1}$ Department of Biological Sciences, Auburn University, Auburn, AL 36849

2 Department of Biology, University of Puerto Rico, Rio Piedras, Puerto Rico

${ }^{3}$ Smithsonian Tropical Research Institute, Apartado 0843-03092, Panama City, Panama 
${ }^{4}$ Laboratoire Écologie, Évolution, Interactions des Systèmes Amazoniens (LEEISA), Université de Guyane, CNRS, IFREMER, 97300 Cayenne, French Guiana *Corresponding author: E-mail: jgo0012@auburn.edu Address: 350 S College St Auburn, AL 36849

\begin{abstract}
The evolution of mimicry in similarly defended prey is well described by Müllerian mimicry theory, which predicts the convergence of warning patterns in order to gain the most protection from predators. However, despite this prediction, we can find great diversity of color patterns amongst Müllerian mimics such as Heliconius butterflies in the neotropics. Furthermore, some species have evolved the ability to maintain multiple distinct warning patterns in single populations, a phenomenon known as polymorphic mimicry. The adaptive benefit of these polymorphisms is questionable since variation from the most common warning patterns is expected to be disadvantageous as novel signals are punished by predators naive to them. In this study we use artificial butterfly models throughout Central and South America to characterize the selective pressures maintaining polymorphic mimicry inHeliconius doris. Our results highlight the complexity of positive frequency-dependent selection, the principal selective pressure driving convergence amongst Müllerian mimics, and its impacts on interspecific variation of mimetic warning coloration. We further show how this selection regime can both limit and facilitate the diversification of mimetic traits.
\end{abstract}

Keywords: Polymorphic mimicry, Müllerian mimicry, Heliconius, diversification, polymorphism.

August $5^{\text {th }}, 2021$

Dear Editor,

I am pleased to submit our manuscript entitled "Balanced polymorphisms and their divergence in a Heliconius butterfly"for consideration as an Ecology and Evolution research article.

In our manuscript, we study the selection pressures on polymorphic and divergent mimetic wing colorations of the aposematic butterfly,Heliconius doris. Using artificial model experiments, we show how wing color polymorphisms are maintained by balancing selection within populations. Further, we show that selective pressures on wing colorations are highly localized and that across large geographical scales, divergence in wing color patterns corresponds to differences in predation pressures. These results are particularly interesting asH. doris is one of few Heliconius species that display polymorphic mimicry and have not experienced a radiation of wing color patterns similar to several other Heliconius species. We discuss how the seeming paradox of polymorphic mimicry in $H$. doris may be maintained and impact the diversification of co-mimics. Collectively, the study establishes $H$. doris wing colorations as an example of polymorphic mimicry and offers insights into the selective pressures that drive the diversification of mimetic warning colorations.

We believe the ecological approach of this study and the contribution of its findings to evolutionary biology make Ecology and Evolution an ideal venue for this manuscript. We expect your readers to find its contents pertinent and useful in understanding the selective pressures behind adaptive radiations and the evolution of polymorphic mimicry.

Sincerely, 


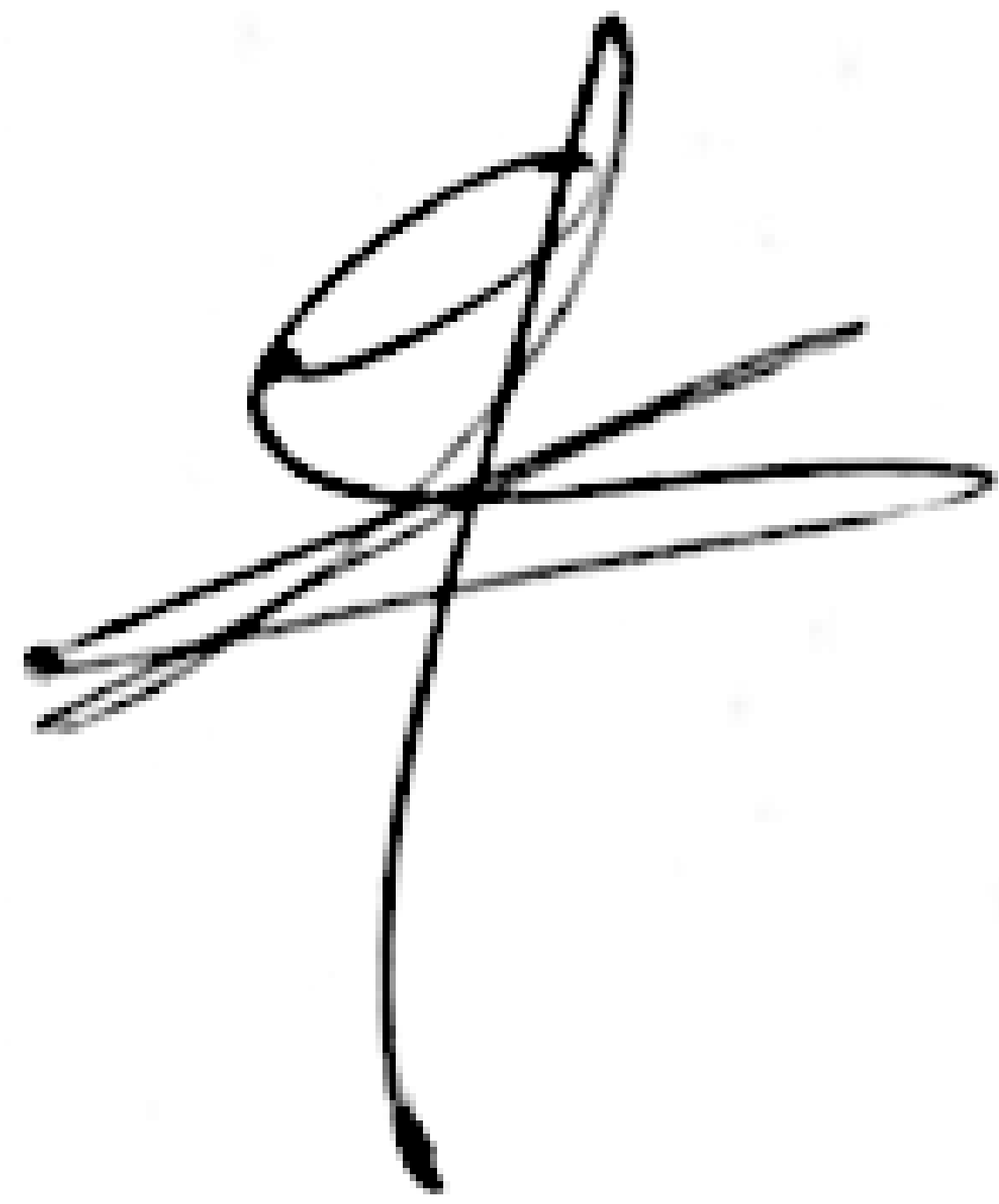

James Ogilvie

On behalf of Steven Van Belleghem, Ryan Range, Riccardo Papa, W. Owen McMillan, Mathieu Chouteau and Brian Counterman

\section{Introduction}

The diversity of color patterns found in the Heliconius butterfly radiation is a striking example of the power of natural selection to generate biodiversity. However, while the most popular theory describing the evolution of these vivid color patterns proposes a framework dissuading from wing pattern diversity, we in fact find dozens of established color patterns throughout the neotropics (Müller, 1879; Joron and Mallet 1998; Mallet and Joron 1999; Moest et al., 2020).

Franz Müller (1879), suggested in his theory that mimicking organisms which are unpalatable, venomous or toxic to predators, benefit from reduced predation by converging on common warning patterns. As these organisms become all the more similar over time, Müllerian mimicry theory predicts that the weight of predation will be optimally shared amongst the mimicking populations. Furthermore, the evolution of stark warning colorations (aposematism), increases the effectiveness of this evolutionary strategy by providing memorable patterns and colors to predators (Su et al., 2015). Examples of animals that through natural 
selection have trodden this evolutionary journey are familiar to many of us for their striking aspects (pitvipers, poison-dart frogs, bumblebees and wasps (Sanders et al., 2006; Symula et al., 2001; Williams, 2007; Boppré et al., 2017). The main mechanism driving this mimicry is known as positive frequency-dependent selection (pFDS), where the most common warning signal is more likely to spread through a population as it will be the most avoided by predators (Müller, 1879). In the past decades, empirical evidence has largely validated pFDS to be a principal selective force maintaining such phenotypic convergence throughout the animal kingdom (Mallet and Barton, 1989; Symula et al., 2001; Dumbacher and Fleischer, 2001; Sanders et al., 2006; Noonan and Comeault, 2009; Borer et al., 2010; Miller and Pawlik, 2013; Chouteau et al., 2016).

Heliconius butterflies are a renowned example of Müllerian mimicry. However, as first described by Henry Walter Bates (1862), the genus clearly demonstrates a diverse array of warning color patterns established throughout several mimicry rings. This presents a challenge to Müller's theory which predicts that the selective pressures enacted by predators attacking novel color patterns should force the convergence of many warning signals into few easily recognizable color patterns. In contrast to this expectation, the co-mimics Heliconius erato and Heliconius melpomene diverged into over 25 geographic color pattern morphs. (Bates, 1862; Turner, 1975; Mallet and Gilbert 1995; Van Belleghem et al., 2020). These mimicry rings maintain homogenous local warning color patterns within their borders through localized pFDS mostly driven by a few insectivorous birds such as rufous-tailed Jacamars and tyrant-flycatchers (Benson, 1972; Chai, 1986; Langham, 2004; Mallet and Barton, 1989; Pinheiro, 2011). However, at the boundaries of these mimicry rings hybridization frequently occurs and results in narrow regions of intermediate color patterns (Mallet, 1986a; Thurman et al., 2019; Edelman et al., 2019). Such phenomena can also be observed in vertebrate Müllerian mimics such as the dendrobatid poison-dart frog radiation (Roland et al., 2017).

In contrast to the homogenous local warning color patterns, some species have evolved the ability to maintain multiple mimetic warning phenotypes in a single population, a phenomenon known as "polymorphic mimicry" (O'Donald and Pilecki, 1970). In these populations, distinct morphs are locally adapted to their environment by sharing distribution with other Müllerian co-mimics (Arias et al., 2016). The selective pressures that allow polymorphic mimicry to evolve and be maintained remains a largely unresolved question. Historically, polymorphy was considered to be a random occurrence with no obvious advantages to the organism bearing it. However, initial evidence in banded land snails (Cain and Sheppard, 1954) and later in a variety of other organisms such as spiders, guppies and wolves (Hendrickx et al., 2015; Hedrick et al., 2016; Hughes et al., 2013), has indicated that polymorphism may serve an adaptive role that can be maintained through sexual selection and possibly promote speciation (Jamie and Meier, 2020). Such a system has been described in Heliconius numata, where polymorphism is considered the result of competing selective pressures on the genomic architecture underlying the trait (Jay et al., 2021).

In this study with test sites throughout Central and South America, we set out to characterize the ecological pressures that drive polymorphism in aposematic butterflies. The Müllerian mimic Heliconius dorisis known for being polymorphic across its entire geographic distribution that spreads across most of South and Central America (Mallet, 1999; Constantino et al., 2005), with both red and blue color morphs found throughout its range. While these two morphs are ubiquitous to all H. doris populations, personal observations point out blue morphs being more abundantly found than red morphs in coastal areas of French Guiana. Additionally, red morphs show a divergence in the red rayed pattern where rays have a broader shape in Central America where red banded co-mimics are common and thinner rays in South America which perfectly match those of the thin red ray mimicry ring of the amazon basin (see Figure 1). Here, we tested if red and blue morphs of $H$. doris reflect predictions of a balanced polymorphism, where we expected both morphs to experience similar predation pressure wherever they are both local. We also used the regional difference in the red H. doris morphs between South and Central America to assess the ability of pFDS to drive adaptive divergence of a balanced polymorphism at varying geographic scales. Furthermore, we tested if the differences in co-mimic frequency in French Guiana from rayed phenotypes in the interior to non-rayed on the coast (Blum, 2008), can drive local differences in predation on $H$. dorismorphs.

Even though Müllerian Mimicry theory predicts warning signal monomorphy over time, we have found the 
selective pressures that allow $H$. doris to maintain multiple warning colors across its range. We have further observed how the same selective forces maintaining this polymorphism also act to drive divergence in warning coloration at large geographical scales.

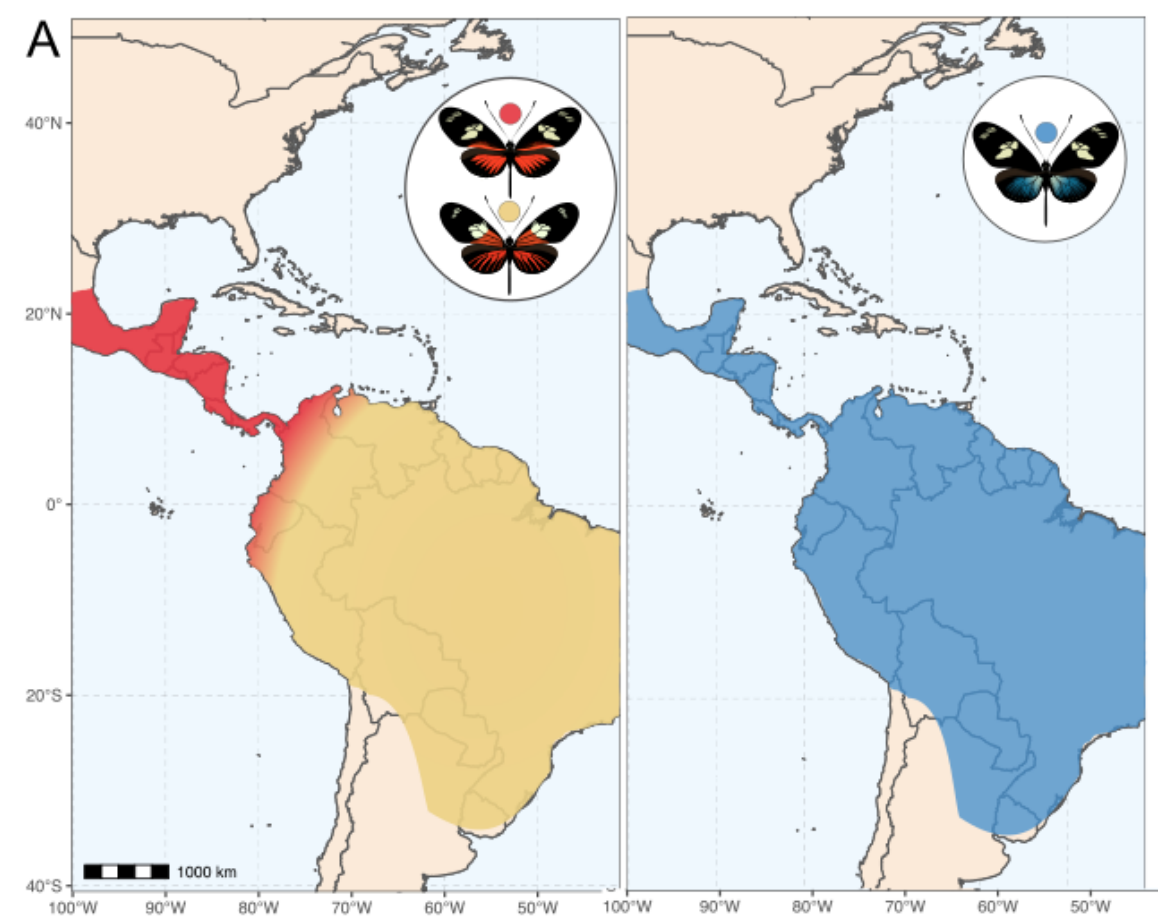

B

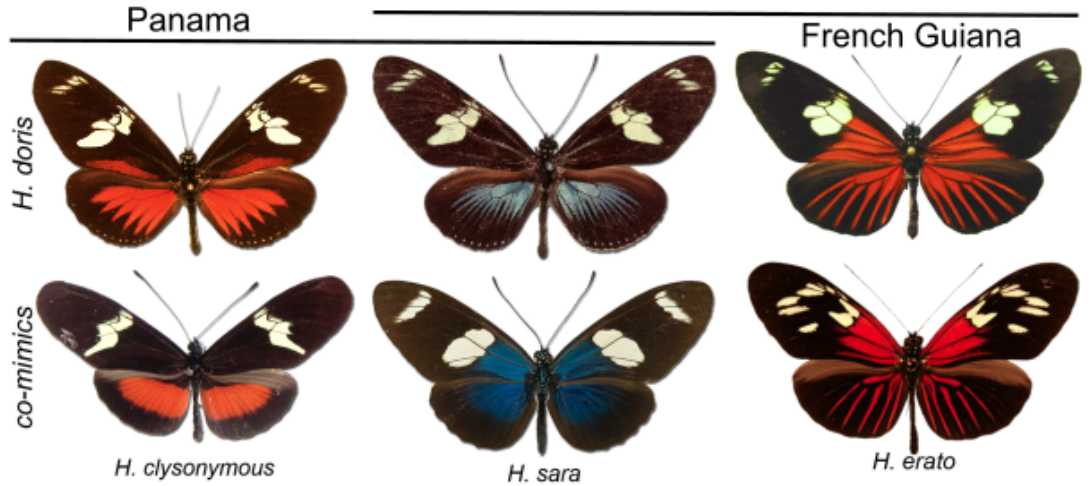

Figure 1. Heliconius doris distribution, polymorphic forms and co-mimics. A. Distribution of blue and divergent red morphs compared to widespread blue morph distribution. B.Heliconius doris morphs (top row) with respective co-mimics (below).

\section{Methods \& Materials}

\section{Experimental locations}

Experiments were conducted at three locations, with two replicate sites at each location. At all sites, Heliconius butterflies, particularly the $H$. doris co-mimics $H$. erato and $H$. sara, are some of the most abundant butterflies present. In addition, $H$. doris has been observed at each of the three locations. Therefore, the local predators should be well-trained for avoiding the local morphs. In Panama we conducted the experiments at two sites along Pipeline Rd. near Gamboa Panama (9.12542, -79.71459). In Panama, red (broad rays) and blue $H$. doris morphs are present, as well as co-mimics for red and blue morphs. In French Guiana, 
experiments were conducted in two locations, inland $(4.57768,-52.39848)$ and coastal $(4.87316,-52.26627)$, with two replicate sites at each location. At the interior French Guiana sites both the red (narrow rays), and blue $H$. doris morphs are present, as well as red and blue co-mimics. At the coastal sites, both the red (narrow rays) and blue $H$. doris morphs are present, but only co-mimics of the blue morph are present. In French Guiana, at around $20 \mathrm{~km}$ inland there is a sharp transition in the co-mimic $H$. erato color patterns, with solid black hindwings (non-mimetic to $H$. doris ) along the coast and red rayed morphs in the interior (mimetic to H. doris ). (Blum, 2008). Based on personal observations and available collections, Heliconius with red ray morphs appear to be largely absent from the coastal areas, therefore predators in the coastal sites have likely had more training to avoid blue, than red warning color morphs.

\section{Artificial Butterfly Models}

We used artificial butterflies to assay predation of $H$. doriswarning colorations in three distinct geographic locations with known divergence in $H$. do ris wing colorations (Panama versus French Guiana red hindwing pattern). Artificial butterfly experiments in natural populations have proven to be efficient means to record predator attacks for several Heliconius species and warning colorations (Arias et al., 2016; Chouteau et al., 2016; Finkbeiner et al., 2018; Seymoure et al., 2018). At each of the three locations in Panama and French Guiana, we used artificial butterflies of threeH. doris warning colorations and the cryptic Pierella hyceta, which we used as a palatable control following the method in Chouteau et al., (2016). This model allowed us to obtain additional data on the intensity of selection at each locality, however it also provided a comparative insight on the selective advantages of crypsis versus aposematism.

Standardized photographs of the ventral and dorsal wings of each butterfly were used and printed on twosided matte photographic paper. (Epson C135041569 paper and L110 Printer). In order to produce a high volume of standardized models, a silicon mold (Mold Star, Smooth-on) was fabricated using clay bodies that were shaped to resembleHeliconius bodies. The paper wings were inserted into each mold along with a thin 20 $\mathrm{cm}$ metal wire before pipetting a mixture of high melting point wax with a black dye and then left to solidify. The different colors on the printed wings were calibrated in Photoshop (Adobe Inc.) and then contrasted with the colors on actual $H$. doris wings by measuring the reflectance spectra of red, black, yellow and blue using a spectrophotometer (HR2000+ES, Ocean Optics) and a deuterium/halogen light source (DH-2000; Ocean Optics) connected to a 3.175-mm diameter sensor (QR600-7-UV125BX; Ocean Optics) inserted in a miniature black chamber. Reflectance spectra were taken at $90^{\circ}$ for all colors except for the blue structural coloration which was taken at $45^{\circ}$ incidence relative to a $99 \%$ reflectance standard (300-700 nm; Spectralon) and to a dark current. Spectra were recorded with SpectraSuite 1.0 software (Ocean Optics). color spectra from real and printed wings were then compared using the method described by Osorio (1998) in Avicol v.6 software (Gomez, 2006). We contrasted blue, black, red and yellow, under two main avian vision systems: blue tit (Parus caeruleus ) for UV vision, with cone proportion and sensitivity as described by Hart et al., (2000), and wedge-tailed shearwater (Puffinus pacificus) as described by Hart (2004) for violet (V) vision. Photoreceptor activity was computed from the Weber fraction (Osorio, 1998), and set to 0.05 for all artificial models. Small gap light conditions, as defined by Endler (1993) from French Guiana were included in all calculations (Thery et al., 2008). Chromatic (Delta S) and achromatic differences (Delta Q) for all colors were found to be under the noticeable threshold for avian vision in UVS and VS $(<1.00$ Just Noticeable Difference units, as in Llaurens et al., (2014), thereby confirming the accuracy in color of our printed wings to real wings (See Table 1).

Using the attached thin metal wire, models were placed on leaves, trunks or twigs in visible, well-lit areas at $10 \mathrm{~m}$ intervals along a $4 \mathrm{~km}$ transect in each site. The placement of each model was carried out so as to mimic the natural perching behavior of Heliconius butterflies and provide a visible target for potential avian predators. The distinct model morphs were placed along the transect in a regular order. From 376 to 416 models were placed per site and left for 72 hours, after which, models were collected. Damage was clearly visible in the malleable wax bodies and paper wings of several models. Damages were catalogued as either (i) "invertebrate attack" when bearing the visible fine marks of arthropod mandibles, often on the wax bodies, (ii) "Avian Attack" when bearing the characteristic U or V shape marks on the wax or (iii) "Unknown 
Predator" when a severe attack was evident but a specific mark was not found, such as when wings were torn or wax bodies broken in pieces. Models that bore attack marks characteristic of invertebrates were not included in the data analysis $(\mathrm{n}=97$ out of 2,271$)$, as there is currently no literature regarding invertebrates carrying the cognitive capacity necessary to make the associations between unpalatability and warning color patterns central to Müllerian mimicry. Furthermore, missing models were also excluded from the analyses as we are unable to determine if they were displaced by falling forest debris, human action or attacked by natural predators.

\section{Data Analysis}

Variation in predation rates amongst the different models in the different regions (counting with two sites as replicates), was assessed by a $\chi^{2}$ test of independence in $\mathrm{R}$ Studio (RStudio Team, 2021). When significant, the Freeman-Tukey deviate (FT) was compared with an alpha from 0.05 to 0.01 criterion corrected for multiple comparisons using a Bonferroni correction, to identify which model morph was attacked significantly more or less than expected based on the null hypothesis of equal attack probability.

\section{Results}

We placed an average of 392 models per site over six sites for a total of 2,356 throughout all our field sites of which 2,271 were recovered $(96.39 \%)$ with 158 showing evidence of an attack event $(6.96 \%)$. In French Guiana, of 1,604 model placements throughout 4 field sites, 1,524 were recovered (95.01\%) and 123 models were attacked $(8.07 \%)$. In Panama, we placed 752 models throughout two field sites of which 747 were recovered (99.34\%) and 35 models were attacked (4.69\%). Attacks were recorded as damage caused on the wax bodies or paper wings by either avian, unknown or invertebrate predators.

We found palatable cryptic models to be similarly attacked to warningly colored phenotypes throughout our sites. This suggests that warning signals are at least as advantageous as crypsis even though they are more easily detected and even more so when co-mimics to a given aposematic signal are frequent (see Figure 4). In contrast, aposematism appears less effective than crypsis when co-mimics are absent (see Figure 3 ).

Balanced polymorphism of aposematic wing colors in H. doris

We tested the prediction that blue and red H. doris morphs experience similar predation where they are both native. For this we conducted FT tests to determine if there were significant differences in attacks on native blue morphs, native red morphs and the controls. Globally, using data from all sites, we found no significant differences in attacks $(\mathrm{N}=1705, \mathrm{p}>0.24)$. To confirm this result was consistent between the two study locations, we conducted similar analyses within French Guiana and Panama. Locally, within Panama and French Guiana, we also found no significant differences in attacks (French Guiana N = 1145, p $>0.073$; Panama: $\mathrm{N}=560, \mathrm{p}>2.306$; Figure 2). This suggests that the blue and red morphs enjoy similar protection from predators wherever they naturally co-occur in populations. 
A

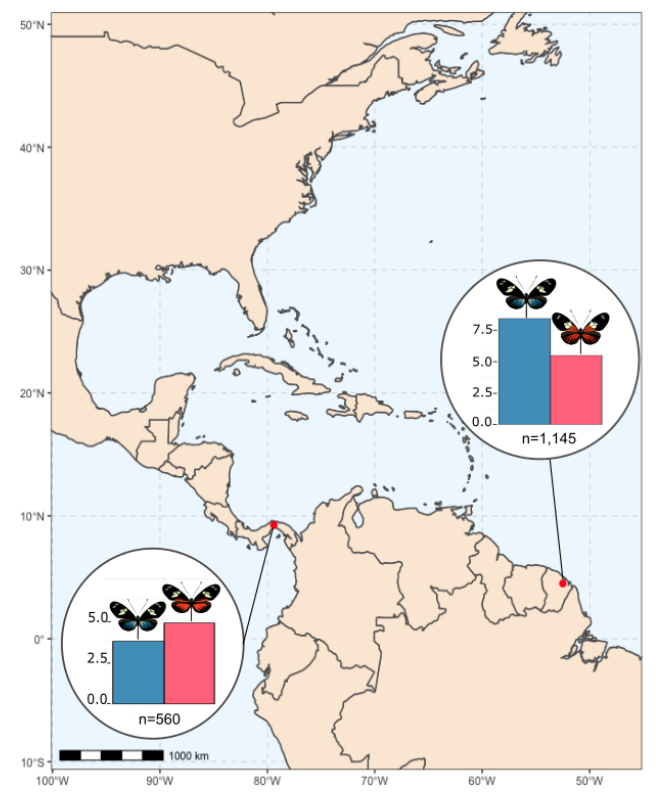

B

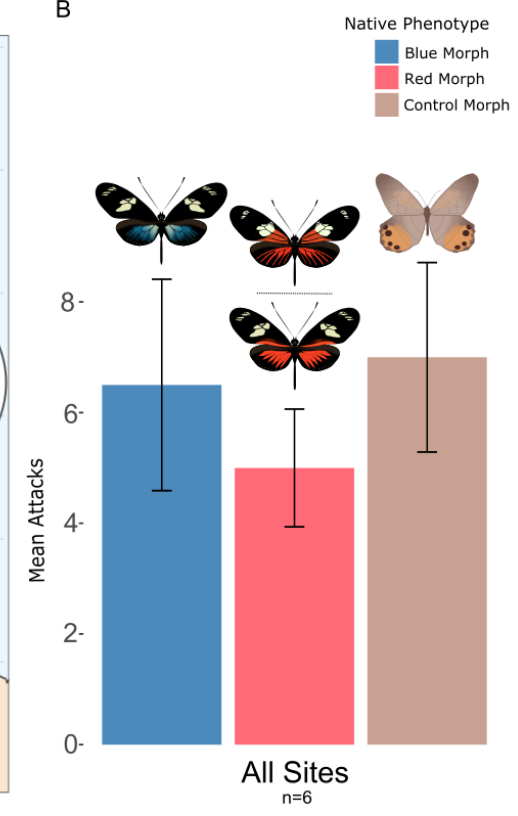

Figure 2. No significant attack differences between $H$. doris coexisting morphs. A. Average amount of attacks on local morphs of $H$. dorisin Panama and French Guiana. B. Average amount of attacks with standard error on individual models representing local $H$. dorismorphs throughout all sites $(\mathrm{n}=6)$. Dashed line separates red morphs corresponding to south and Central America, respectively. Statistical tests were performed with raw attack numbers.

\section{Regional divergence in balanced polymorphism}

Next, we tested for evidence of adaptive divergence of warning coloration among populations for $H$. doris . For this, we tested the prediction that divergence in red color morphs between Panama and French Guiana $H$. doris populations resulted in greater predation on non-native red morphs at each locality.

Of the two red morphs with differing hindwing rays corresponding to Central America or South America, we expected predation rates to show signs of differential avoidance based on frequency of a given signal in each region. Specifically, we predicted that local phenotypes would be significantly avoided relative to the exotic phenotypes. For this test we used FT tests to detect differences in attacks on native, non-native reds, and controls. In French Guiana, we found significant differences in attacks on red morphs at coastal and inland sites. At coastal sites we found significantly greater attacks on the non-native red morph than native reds and controls, as would be expected since the local predators would have been naive to this red warning wing pattern $(\mathrm{n}=560 ; \mathrm{p}<0.0365$; Figure 3$)$. However, at the inland sites the non-native morphs were not attacked significantly more than the controls. Rather, we found that the native reds were attacked significantly less at inland sites $(\mathrm{n}=584 ; \mathrm{p}<0.023$; Figure 3$)$. Interestingly, this finding fits the expectations of $\mathrm{pFDS}$, as red co-mimics are known to be at higher frequencies at inland than coastal sites in French Guiana. In Panama, we found no evidence of differences in attacks on native reds, non-native reds or controls. 
A

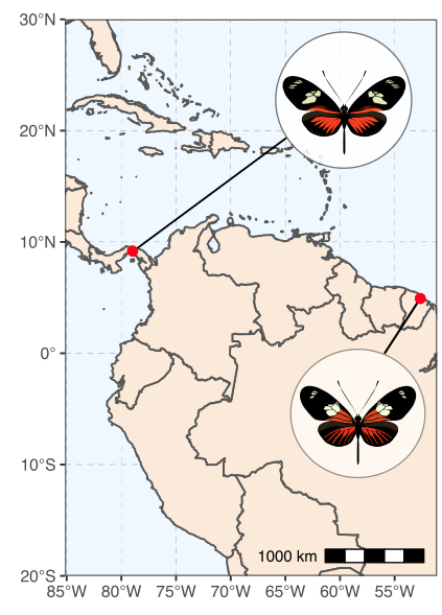

B

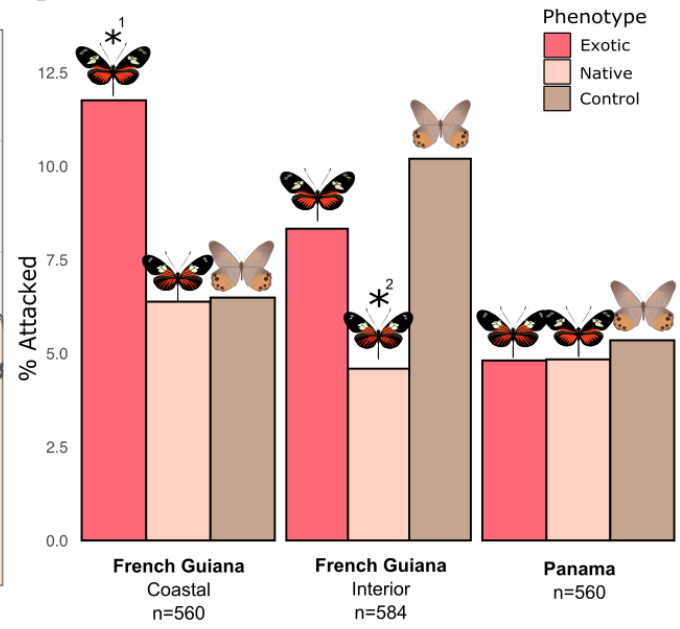

Figure 3 . Differences in attacks on native and foreign red morphs. A. Divergent red morphs of $H$. doris at study sites (Panama and French Guiana). B. Percentage of attacks on native and exotic red phenotypes shows a significantly higher predation on exotic phenotypes in the coastal region of French Guiana and significantly lower predation on native phenotypes in the interior zone, where red co-mimics are abundant $\left({ }^{* 1} \mathrm{p}<0.0365,{ }^{* 2} \mathrm{p}<0.023\right.$, Freeman-Tukey [FT] test). Statistical analyses used raw attack numbers, percentages shown here for clarity. Bar plots represent three separate FT tests.

\section{Co-mimics drive local variation in pFDS on balanced polymorphism}

Lastly, we tested for variation in local selection to explain the geographic differences in the balanced warning color polymorphism in H. doris. For this, we leveraged differences in the presence of red comimics at coastal versus inland sites in French Guiana. At coastal sites, H. erato and H. melpomene morphs are characterized by an all-black hindwing that lacks red rays. However, at inland sites, $H$. erato and $H$. melpomene morphs have red rays that are strikingly similar to $H$. doris red rays. At coastal and inland sites $H$. sara, which is a co-mimic of the blue warning color, is found at high frequencies. Similar to the analyses above, we used FT tests to determine if attacks were different on red morphs, blue mophs or controls, in either coastal or inland sites. We predict that pFDS would result in red morphs being attacked more at coastal sites that lack the red co-mimics.

We found no evidence of red morphs being attacked significantly more than blue morphs or the controls at the coastal sites $(\mathrm{n}=557 ; \mathrm{p}>1.0)$. However, at the inland sites we found that the red morphs were attached significantly less than blue morphs and controls $(\mathrm{n}=588 ; \mathrm{p}<0.027)$. These results suggest that the presence of co-mimics confers greater protection for red morphs, however a lack of co-mimics does not appear to result in greater predation pressures for the red morphs. 

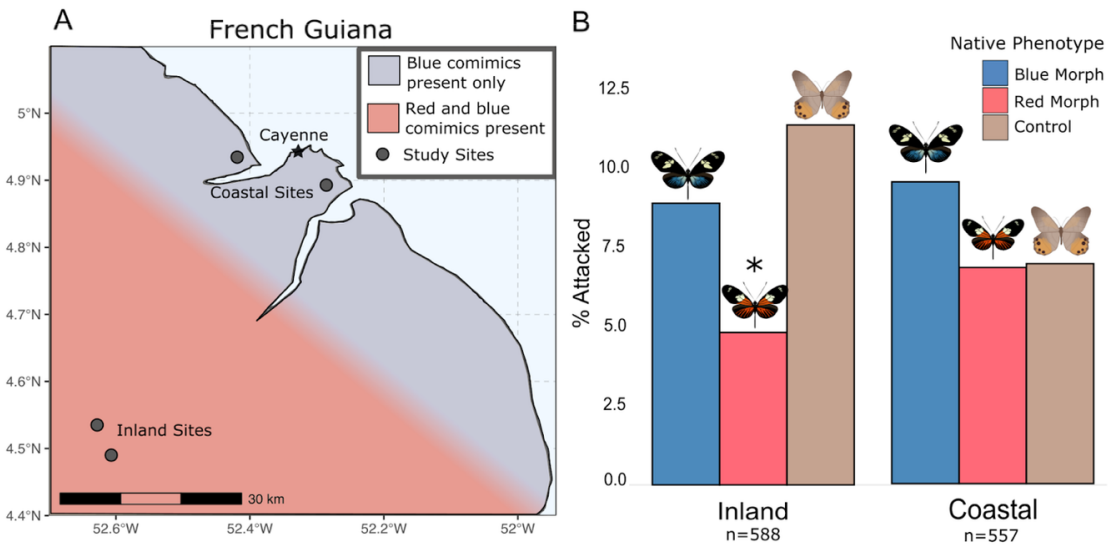

Figure 4. Red morphs attacked less at sites with red mimicry-ring present.A. Locations of study sites and co-mimic distributions in French Guiana. B. Attacks of different H. doris morphs and controls at inland and coastal sites that differ in local mimicry rings show significant protection of red morphs at inland sites where red co-mimics are present $(* p<0.027$, Freeman-Tukey test). Statistical analyses used raw attack numbers, percentages shown here for clarity. Bar plots represent two separate FT tests.

\section{Discussion}

Striking similarity of predation pressures across Heliconius species and populations

Our results of predator attacks on Heliconius models correspond to the attack patterns observed in markrelease-recapture experiments, where naïve predators significantly attack novel, exotic patterns relative to native, common warning patterns (Mallet and Barton, 1989; Langham, 2004). As may be expected, attacks of live prey showed much greater differences for exotic and native morphs (36-37\% versus $0 \%$, respectively), than we observed with artificial models (5-11.5\% versus $4-6.5 \%$, respectively; see Figure 3 ). This difference between model and live prey experiments likely results from the inability of models to replicate physical and behavioral cues recognized by potential predators (i.e. crawling, wing flapping, flight). Although the attack numbers on models likely do not reflect realized predation rates of live butterflies, they do provide reliable means to compare relative predation pressures due to differences in visual cues.

Importantly, there is a remarkable similarity in attacks ofHeliconius models in studies that span a variety of species and geographic locations over the past decade (Arias et al., 2016; Chouteau et al., 2016; Finkbeiner et al., 2012; Finkbeiner et al., 2014; Finkbeiner et al., 2018; Merrill et al., 2012; Seymoure et al., 2018). Attack percentages in these studies range from 4-15\%, which overlaps our observed attack percentages that ranged from $4-12 \%$ on $\mathrm{H}$. doris morphs. This consistency in attacks of models may reflect the similarity in avian predation pressures amongHeliconius species and populations. The Rufous Tailed Jacamar (Galbula ruficauda) has been reported as a common predator ofHeliconius in western South America (Mallet \& Barton, 1989) and Central America (Dell'aglio et al., 2016; Langham, 2004). In line with these reports, we observed a Rufous Tailed Jacamar successfully attack a Heliconius (likelyHeliconius sara) at one of our inland experimental sites in French Guiana. Collectively, this supports that Jacamars may be a common predator driving similar attack rates in the various Heliconiusmodel experiments. Therefore, we can make direct comparisons among these studies and general inferences about the relative effectiveness of specific aposematic color patterns and corresponding selective pressures.

\section{The paradox of polymorphic mimicry in $H$. doris}

The strong selective forces that drive Müllerian mimicry are predicted to result in monomorphism among mimicking species, yet as in $H$. doris , there are many examples of polymorphic mimicry in nature. Our study sheds some light on how this paradox may be achieved. Our results suggest that pFDS can vary at regional scales, and is constrained to knowledgeable predator communities which are savvy to the aposematic forms 
found only in their local ecosystem (Chouteau et al., 2016; Langham, 2004). For example, over the relatively short distance of $\sim 30 \mathrm{~km}$, we found significant differences in the attacks on native red morphs of $H$. doris , with significantly less attacks occurring at the sites where other red co-mimics are present. This suggests the predator community knowledge was quite distinct at the different sites and corresponds to reports of Jacamars having rather narrow home ranges (Chai, 1986). However, this begs the question of "how do the red H. doris persist in areas lacking red co-mimics?", as we would expect the lack of co-mimics to result in higher predation and eventual removal of the red morph from the population.

A possible explanation lies in the dispersal behaviour from nearby populations where red co-mimics are present and the red $H$. dorismorphs have greater protection. Other Heliconius species such as H. erato and H. melpomene have an estimated dispersal range of only $\sim 2.5-5 \mathrm{~km}$ (Mallet, 1986a; Mallet et al., 1990), as a result of their "trap-line" behaviors as adults (Young \& Montgomery, 2020). However, it has been suggested that Heliconius doris may disperse much larger distances immediately post pupal eclosion, which could reduce chances of sib-competition and sib-matings (Mallet, 1999). Heliconius doris females are known to gather in groups and lay eggs on single plants, often even the same leaf, which we observed first-hand in French Guiana. This results in a mass of gregarious larvae that will often fully consume all leaves and tendrils on thePassiflora host. After consumption, an individual host plant can require several years to reach a size sufficient to host another population of $\mathrm{H}$. doris eggs. It would then likely benefit newly eclosed females to disperse larger distances than otherHeliconius species that tend to oviposit much fewer eggs in close proximity. Therefore, it is possible that group egg laying, and relatively greater dispersal in H. doris could drive a "mismatch" of warning colors in the distribution of Heliconiusco-mimetic species, as seen in French Guiana. This dispersal-based hypothesis would result in sink populations for $H$. doris morphs, where the red co-mimics are lacking, that are continuously replenished from source populations where red morphs have greater protection. It is difficult to understand how this could be an evolutionarily stable strategy and dispersal data for H. doris are lacking to support such a source-sink model for the presence of red H. doris morphs where the co-mimics are absent.

Another important aspect that could explain the distribution of red morphs and polymorphic mimicry in $H$. doris is the genetic basis for the color variation. In H. numata, polymorphic color patterns result from allelic changes at a single locus, $P$ (Joron et al., 2006). More specifically, the different color patterns result from varying combinations of chromosomal inversions across the $P$ locus (Joron et al., 2011). The color pattern variation is maintained in local populations through disassortative mating (Maisonneuve et al., 2021), a form of negative frequency-dependent selection where rare morphs are preferred mates resulting in offspring of variable colorations. Since the color pattern differences are controlled by a single locus, and the different alleles cannot recombine due to the inverted orientations (Jay et al., 2021), disassortative mating will keep producing color pattern variation in perpetuity. In $H$. numata, each of the different color patterns also correspond to local co-mimics, and different morphs appear to share similar predation pressures (Chouteau et al., 2016). We propose that a similar system may have evolved in H. doris, with non-recombining alleles at a single locus controlling color pattern variation coupled with disassortative mating as such a system would result in distinct red and blue morphs in each generation across the H. doris range. Currently, there is no data for the inheritance of color patterns or mate preference in $H$. doris, which would be vital for determining how polymorphic mimicry is maintained in the species.

\section{Positive FDS as an agent of convergence and divergence}

Positive FDS is the evolutionary force that drives mimicry inHeliconius butterflies (Chouteau et al., 2016). It is the result of local predators learning through experience to avoid the aposematic signals of the most common unpalatable prey. Müllerian mimicry posits that unpalatable prey will benefit by sharing similar aposematic signals thereby allowing them to share the cost of training the local prey population. As we saw in our study, local pFDS can be a strong evolutionary force that can vary over relatively short distances. Within Heliconius populations, pFDS will drive mimics to a local optima color pattern that often varies little within or between species. In our study, this is clearly seen in the French Guiana red morphs whose hindwing rays are near perfect copies of the hindwing rays of $\mathrm{H}$. erato, the most common Heliconius in French Guiana 
with a red rayed color pattern. In contrast the blue H. doris are co-mimics of $H$. sara, which do not have blue rays, but rather a blue iridescence that extends broadly from the proximal region of the forewings (Figure 1). Correspondingly, the shape of the blue rays of $H$. doris are starkly different from the shape of the red rays. Therefore, not only has pFDS driven a difference in hindwing color, but also the shape of the color pattern. This is further seen in Panama, where again the red H. doris morphs are shaped differently than those in French Guiana, where the red ray shape is a near perfect to red co-mimics in Panama (Figure 1). This variation in color pattern shape exemplifies the power of pFDS to drive convergence (or advergence) within local populations.

In contrast to our results indicating local advergence, the difference in color pattern shape between regions demonstrates the ability of pFDS to drive divergence within species. Across its range, $H$. dorispresently exhibits divergent red color pattern morphs, that in French Guiana were distinguishable by the local predator community.

In Panama, the local predators attacked the models much less and did not show evidence that they distinguished between the divergent red morphs. We suggest this may be a result of more generalized avoidance in the Panama populations, which would result in less attacks on all morphs, as we saw. It is worth noting that this site in Panama, near the Gamboa Smithsonian Tropical Research Station, has been the location of manyHeliconius studies (live and model based) over the years (Seymoure et al., 2018; Dell'aglio et al., 2016; Finkbeiner et al., 2014; Merrill et al., 2012), and nearby there has been many anthropogenic changes to the environment that collectively could have influence on the local predator community.

We found that even at small regional scales, selection on mimetic warning patterns differs depending on local predator communities. Although Müllerian Mimicry theory predicts mimicking species to achieve monomorphism in color patterns overtime, we demonstrate that $H$. doris maintains a balance of multiple warning colors across its range. Further, we find that the same selective forces acting to maintain the balanced polymorphism, also drive divergence in warning coloration across its range. These results highlight the complex nature of pFDS and the impacts it has on interspecific variation of mimetic warning colorations. Collectively, our study as well as other model studies such as those of color polymorphisms in H. numata (Chouteau et al., 2016) and Peruvian dart frogs (Chouteau \& Angers, 2011), have demonstrated that pFDS can simultaneously be an agent that both limits and facilitates diversification of mimetic traits.

\section{Literature Cited}

Arias, M., le Poul, Y., Chouteau, M., Boisseau, R., Rosser, N., Théry, M., \& Llaurens, V. (2016). Crossing fitness valleys: empirical estimation of a fitness landscape associated with polymorphic mimicry. Proceedings. Biological sciences, 283(1829), 20160391. https://doi.org/10.1098/rspb.2016.0391 Aubier, T.G. and Sherratt, T.N. (2015). Diversity in Müllerian mimicry: The optimal predator sampling strategy explains both local and regional polymorphism in prey. Evolution, 69: 2831-2845. doi:10.1111/evo.12790Avril, A., Purcell, J., Brelsford, A., \& Chapuisat, M. (2019). Asymmetric assortative mating and queen polyandry are linked to a supergene controlling ant social organization. Molecular Ecology, 28, 1428- 1438.https://doi.org/10.1111/mec.14793Bates, H. W. (1862). Contributions to an insect fauna of the Amazon Valley. Lepidoptera: Heliconidae. Transactions of the Linnean Society London. 23:495-566. Benson W. W. (1971). Evidence for the evolution of unpalatability through kin selection in the Heliconiinae (Lepidoptera). Am. Nat. 105, 213-226. doi:10.1086/282719 Benson W. W. (1972). Natural Selection for Müllerian Mimicry in Heliconius erato in Costa Rica. Science (New York, N.Y.), 176 (4037), 936-939. https://doi.org/10.1126/science.176.4037.936 Blum M. J. (2008). Ecological and genetic associations across a Heliconius hybrid zone. Journal of evolutionary biology, 21(1), 330-341. https://doi.org/10.1111/j.14209101.2007.01440.x Boppré, M., Vane-Wright, R. I., \& Wickler, W. (2016). A hypothesis to explain accuracy of wasp resemblances. Ecology and evolution, 7(1), 73-81.https://doi.org/10.1002/ece3.2586Borer, M., Van Noort, T., Rahier, M., \& Naisbit, R. E. (2010). Positive frequency-dependent selection on warning color in Alpine leaf beetles. Evolution; international journal of organic evolution, 64 (12), 3629-3633. https://doi.org/10.1111/j.1558-5646.2010.01137.x Brower A. (1996). Parallel race formation and the evolution of mimicry in Heliconius butterflies: a phylogenetic hypothesis from mitochondrial DNA sequences. 
Evolution; international journal of organic evolution, 50(1), 195-221. https://doi.org/10.1111/j.15585646.1996.tb04486.x Brown, K. S., and W. W. Benson. (1974). Adaptive polymorphism associated with multiple Müllerian mimicry in Heliconius numata. Biotropica6:205-228. Bulmer, M.G. (1972). Multiple niche polymorphism. Am. Nat. 106, 254-257 Cain A.J. \& Sheppard PM. (1954). Natural selection in Cepaea.Genetics 39: 89-116. Chai P. (1986). Field observations and feeding experiments on the responses of rufous-tailed jacamars (Galbula ruficauda) to free-flying butterflies in a tropical rainforest. Biol. J. Linn. Soc. 29, 161189. https://doi:10.1111/j.1095-8312.1986.tb01772. Chouteau, M., Arias, M., \& Joron, M. (2016). Warning signals are under positive frequency-dependent selection in nature. Proceedings of the National Academy of Sciences of the United States of America, 113(8), 2164-2169. https://doi.org/10.1073/pnas.1519216113 Chouteau, M., Llaurens V., Piron-Prunier F., Joron M. (2017). Polymorphism at a mimicry supergene maintained by opposing frequency-dependent selection pressures. Proceedings of the National Academy of Sciences, 201702482; https://doi.org/.1073/pnas.1702482114 Concha, C., Wallbank, R. W. R., Hanly, J. J., Fenner, J., Livraghi, L., Rivera, E. S., Paulo D.S., Arias C., Vargas M., Sanjeev M., Morrison C., Tian D., Aguirre P., Ferrara S., Foley J., Pardo-Diaz C., Salazar C., Linares M., Massardo D., Counterman B.A., Scott M.J., Jiggins C.D., Papa R., Martin A., McMillan W.O. (2019). Interplay between Developmental Flexibility and Determinism in the Evolution of Mimetic Heliconius Wing Patterns. Current biology : CB, 29(23), 3996-4009.e4. https://doi.org/10.1016/j.cub.2019.10.010 Constantino, L.M., Zulma N. and Corredor G. (2005). Chromatic polymorphism of Laparus doris obscurus and determination of the phenotypic frequency through intraspecific crosses of three populations in the departments of Valle and Caldas, Colombia. Boletín científico. Museo de Historia Natural. Universidad de Caldas 9: 222-237. Dell'Aglio, D.D., Stevens, M. and Jiggins, C.D. (2016), Avoidance of an aposematically colored butterfly by wild birds in a tropical forest.Ecol Entomol, 41: 627-632.https://doi.org/10.1111/een.12335Doktorovová, L., Exnerová, A., Hotová Svádová, K., Štys, P., Adamová-Ježová, D., Zverev, V., Kozlov, M.V., Zvereva, et al., (2019). Differential Bird Responses to Colour Morphs of an Aposematic Leaf Beetle may Affect Variation in Morph Frequencies in Polymorphic Prey Populations. Evol Biol 46, 35-46.https://doi.org/10.1007/s11692-018-94658 Dumbacher, J. P., \& Fleischer, R. C. (2001). Phylogenetic evidence for colour pattern convergence in toxic pitohuis: Müllerian mimicry in birds?. Proceedings. Biological sciences, 268(1480), 1971-1976. https://doi.org/10.1098/rspb.2001.1717 Edelman, N. B., Frandsen, P. B., Miyagi, M., Clavijo, B., Davey, J., Dikow, R. B., García-Accinelli, G., Van Belleghem, S. M., Patterson, N., Neafsey, D. E., Challis, R., Kumar, S., Moreira, G., Salazar, C., Chouteau, M., Counterman, B. A., Papa, R., Blaxter, M., Reed, R. D., Dasmahapatra, K. K., ... Mallet, J. (2019). Genomic architecture and introgression shape a butterfly radiation. Science (New York, N.Y.), 366(6465), 594-599. https://doi.org/10.1126/science.aaw2090 Fisher, K. A. (1958). The Genetical Theory of Natural Selection. 2nd Ed. Dover, N.Y Finkbeiner, S. D., Briscoe, A. D., \& Reed, R. D. (2012). The benefit of being a social butterfly: communal roosting deters predation. Proceedings. Biological sciences, 279(1739), 2769-2776. https://doi.org/10.1098/rspb.2012.0203 Finkbeiner, S. D., Briscoe, A. D., \& Reed, R. D. (2014). Warning signals are seductive: relative contributions of color and pattern to predator avoidance and mate attraction in Heliconius butterflies. Evolution; international journal of organic evolution, 68(12), 3410-3420. https://doi.org/10.1111/evo.12524 Finkbeiner, S. D., P. A. Salazar, S., Nogales, C. E. Rush, A. D. Briscoe, R. I. Hill, M. R. Kronforst, K. R. Willmott, and S. P. Mullen. (2018). Frequency-dependence shapes the adaptive landscape of imperfect Batesian mimicry. Proceedings of the Royal Society. B 285. https://doi.org/10.1098/rspb.2017.2786 Forsman, A., Ahnesjo, J., Caesar, S., \& Karlsson, M. (2008). A model of ecological and evolutionary consequences of color polymorphism. Ecology, 89(1), 34-40. https://doi.org/10.1890/07-0572.1 Galeotti, P. and Rubolini, D. (2004). The niche variation hypothesis and the evolution of color polymorphism in birds: a comparative study of owls, nightjars and raptors. Biol. J. Linn. Soc. 82, 237-248 Gilbert L.E., Futuyma D.M., Slatkin M. (1983). Coevolution and mimicry.Coevolution. pp. 263-281. Sunderland: Sinauer Associates Inc. Gomez D. (2006). AVICOL, a program to analyse spectrometric data. Available at https://sites.google.com/site/avicolprogram/. Accessed September 28 2018. Getty T. (1985). Discriminability and the sigmoid functional response: how optimal foragers could stabilize model-mimic complexes. Am. Nat. 125, 239-256. https://doi.org/10.1086/284339 Harper, G. R., \& Pfennig, D. W. (2007). Mimicry on the edge: why do mimics vary in resemblance to their model in different parts of their geographical range?. 
Proceedings. Biological sciences, 274(1621), 1955-1961.https://doi.org/10.1098/rspb.2007.0558Hart, N. S., Partridge, J. C., Cuthill, I. C., \& Bennett, A. T. (2000). Visual pigments, oil droplets, ocular media and cone photoreceptor distribution in two species of passerine bird: the blue tit (Parus caeruleus L.) and the blackbird (Turdus merula L.). Journal of comparative physiology. A, Sensory, neural, and behavioral physiology, 186(4), 375-387. https://doi.org/10.1007/s003590050437 Hart N. S. (2004). Microspectrophotometry of visual pigments and oil droplets in a marine bird, the wedge-tailed shearwater Puffinus pacificus: topographic variations in photoreceptor spectral characteristics. The Journal of experimental biology, 207(Pt 7), 1229-1240. https://doi.org/10.1242/jeb.00857 Hedrick, P. W., Smith, D. W., \& Stahler, D. R. (2016). Negative-assortative mating for color in wolves. Evolution; international journal of organic evolution, 70 (4), 757-766. https://doi.org/10.1111/evo.12906 Hendrickx, F., Vanthournout, B. and Taborsky, M. (2015), Selection for costly sexual traits results in a vacant mating niche and male dimorphism. Evolution, 69: 2105-2117.https://doi.org/10.1111/evo.12720Hines, H. M., Counterman, B. A., Papa, R., Albuquerque de Moura, P., Cardoso, M. Z., Linares, M., Mallet, J., Reed, R. D., Jiggins, C. D., Kronforst, M. R., \& McMillan, W. O. (2011). Wing patterning gene redefines the mimetic history of Heliconius butterflies. Proceedings of the National Academy of Sciences of the United States of America, 108(49), 19666-19671. https://doi.org/10.1073/pnas.1110096108 Hughes, K., Houde, A., Price, A. Rodd, H. (2013). Mating advantage for rare males in wild guppy populations. Nature 503, 108-110. https://doi.org/10.1038/nature12717 Jamie, G., Meier, J. (2020). The Persistence of Polymorphisms across Species Radiations. Trends In Ecology and Evolution. Cell Press.https://doi.org/10.1016/j.tree.2020.04.007Jay P., Whibley A., Frezal L., Rodriguez de Cara M. A., Nowell R. W., Mallet J., DasmahapatraK. K., Joron M. (2018). Supergene evolution triggered by the introgression of a chromosomal inversion. Current Biology. 28, 1839-1845.e3. https://doi.org/10.1016/j.cub.2018.04.072pmid:29804810 Jay P., Chouteau M., Whibley A., Bastide H., Parrinello H., Llaurens V., Joron M. (2021). Mutation load at a mimicry supergene sheds new light on the evolution of inversion polymorphisms. Nat Genet.53(3):288-293. https://doi.org/10.1038/s41588-02000771-1 Joron M., Papa R., Beltran M., Chamberlain N., Mavarez J., Baxter S., Abanto M., Bermingham E., Humphrey S.J., Rogers J., Beasley H., Barlow K., ffrench-Constant R.H., Mallet., McMillan W.O., Jiggins C.D. (2006). A Conserved Supergene Locus Controls Colour Pattern Diversity in Heliconius Butterflies. PLoS Biol 4(10): e303.https://doi.org/10.1371/journal.pbio.0040303Joron M., Frezal L, Jones R.T., Chamberlain N.L., Lee S.F., Haag C.R., Whibley A., Becuwe M., Baxter S.W., Ferguson L., Wilkinson P.A., Salazar C., Davidson C., Clark R., Quail M.A., Beasley H., Glithero R., Lloyd C., Sims S., Jones M.C., Rogers J., Jiggins C.D., ffrench-Constant R.H. (2011). Chromosomal rearrangements maintain a polymorphic supergene controlling butterfly mimicry. Nature, 477(7363), 203-206. https://doi.org/10.1038/nature10341 Joron, M., \& Mallet, J. L. (1998). Diversity in mimicry: paradox or paradigm?. Trends in ecology \& evolution, 13(11), 461-466. https://doi.org/10.1016/s0169-5347(98)01483-9 Kapan, D. (2001) Three-butterfly system provides a field test of Mullerian mimicry . Nature 409, 338-340 https://doi.org/10.1038/35053066 Kawecki, T.J.; Ebert, D. (2004) Conceptual issues in local adaptation. D Journal: ECOL LETT, 7 (12): 1225-1241 Kokko H, Mappes J, Lindstrom L. (2003) Alternative prey can change model-mimic dynamics between parasitism and mutualism. Ecol. Lett. 6, 1068-1076. https://doi.org/10.1046/j.1461-0248.2003.00532.x Kozak, K. M., Wahlberg, N., Neild, A. F., Dasmahapatra, K. K., Mallet, J., \& Jiggins, C. D. (2015). Multilocus species trees show the recent adaptive radiation of the mimetic heliconius butterflies. Systematic biology, 64(3), 505-524. https://doi.org/10.1093/sysbio/syv007 Kronforst, M. R., Young, L. G., Kapan, D. D., McNeely, C., O'Neill, R. J., \& Gilbert, L. E. (2006). Linkage of butterfly mate preference and wing color preference cue at the genomic location of wingless. Proceedings of the National Academy of Sciences of the United States of America, 103(17), 6575-6580. https://doi.org/10.1073/pnas.0509685103 Kronforst, M. R., \& Papa, R. (2015). The functional basis of wing patterning in Heliconius butterflies: the molecules behind mimicry. Genetics, 200(1), 1-19. https://doi.org/10.1534/genetics.114.172387 Kupper, C., Stocks, M., Risse, J. E., Dos Remedios, N., Farrell, L. L., McRae, S. B., Morgan, T. C., Karlionova, N., Pinchuk, P., Verkuil, Y. I., Kitaysky, A. S., Wingfield, J. C., Piersma, T., Zeng, K., Slate, J., Blaxter, M., Lank, D. B., \& Burke, T. (2016). A supergene determines highly divergent male reproductive morphs in the ruff. Nature genetics, 48(1), 79-83.https://doi.org/10.1038/ng.3443Langham G. M. (2004). Specialized avian predators repeatedly attack novel color morphs of Heliconius butterflies. Evolution;international journal 
of organic evolution, 58(12), 2783-2787. https://doi.org/10.1111/j.0014-3820.2004.tb01629.x Le Poul Y., Whibley A., Chouteau M., Prunier F., LLaurens V., Joron M. (2014). Evolution of dominance mechanisms at a butterfly mimicry supergene. Nature Communications 5, 5644 https://doi.org/10.1038/ncomms6644 Llaurens, V., Whibley, A., \& Joron, M. (2017). Genetic architecture and balancing selection: the life and death of differentiated variants. Molecular ecology, 26(9), 2430-2448. https://doi.org/10.1111/mec.14051 Maisonneuve, L., Chouteau, M., Joron, M., \& Llaurens, V. (2021). Evolution and genetic architecture of disassortative mating at a locus under heterozygote advantage. Evolution; international journal of organic evolution, 75(1), 149-165. https://doi.org/10.1111/evo.14129 Mallet, J. (1986a). Dispersal and gene flow in a butterfly with home range behavior: Heliconius erato (Lepidoptera: Nymphalidae).Oecologia 68, 210-217.https://doi.org/10.1007/BF00384789Mallet, J. (1986b). Hybrid zones in Heliconius butterflies in Panama, and the stability and movement of warning color dines. Heredity,56, 191-202. Mallet, J. (1989). The genetics of warning color in Peruvian hybrid zones of Heliconius erato and $H$. melpomene. Proc $R$ Soc B. 236:163-185. Mallet, J., \& Barton, N. H. (1989). STRONG NATURAL SELECTION IN A WARNING-COLOR HYBRID ZONE. Evolution; international journal of organic evolution, 43(2), 421431. https://doi.org/10.1111/j.1558-5646.1989.tb04237.x Mallet, J., Barton, N., Lamas, G., Santisteban, J., Muedas, M., \& Eeley, H. (1990). Estimates of selection and gene flow from measures of cline width and linkage disequilibrium in heliconius hybrid zones. Genetics, 124(4), 921-936. Mallet, J. (1993). Speciation, raciation, and color pattern evolution inHeliconius butterflies: the evidence from hybrid zones. Pp. 226-260 in R. G. Harrison, ed. Hybrid zones and the evolutionary process. Oxford Univ. Press, New York Mallet, J. (1999). Causes and Consequences of a Lack of Coevolution in Mullerian mimicry. Evolutionary Ecology, 13(7-8), 777-806. https://doi.org/10.1023/a:1011060330515 Mallet, J. and M. Joron (1999). Evolution of diversity in warning color and mimicry: polymorphisms, shifting balance, and speciation. Annual Review of Ecology and Systematics 30: 201-233. Mallet, J. (2010). Shift happens! Shifting balance and the evolution of diversity in warning color and mimicry. Ecological Entomology, 35, 90-104 Martin, A., McCulloch, K. J., Patel, N. H., Briscoe, A. D., Gilbert, L. E., \& Reed, R. D. (2014). Multiple recent co-options of Optix associated with novel traits in adaptive butterfly wing radiations. EvoDevo, 5(1), 7. https://doi.org/10.1186/20419139-5-7 Merrill, R. M., Wallbank, R. W., Bull, V., Salazar, P. C., Mallet, J., Stevens, M., \& Jiggins, C. D. (2012). Disruptive ecological selection on a mating cue. Proceedings. Biological sciences, 279(1749), 4907-4913. https://doi.org/10.1098/rspb.2012.1968 Merrill, R. M., Dasmahapatra, K. K., Davey, J. W., Dell'Aglio, D. D., Hanly, J. J., Huber, B., Jiggins, C. D., Joron, M., Kozak, K. M., Llaurens, V., Martin, S. H., Montgomery, S. H., Morris, J., Nadeau, N. J., Pinharanda, A. L., Rosser, N., Thompson, M. J., Vanjari, S., Wallbank, R. W., \& Yu, Q. (2015). The diversification of Heliconius butterflies: what have we learned in 150 years?. Journal of evolutionary biology, 28(8), 1417-1438. https://doi.org/10.1111/jeb.12672 Miller AM, Pawlik JR (2013). Do coral reef fish learn to avoid unpalatable prey using visual cues? Anim Behav 85(2):339-347. Moest M., Van Belleghem S.M., James J.E., Salazar C., Martin S.H., Barker S.L., Moreira G.R.P., Merot C., Joron, M., Nadeau N.J., Steiner F.M. \& Jiggins C.D. (2020) Selective sweeps on novel and introgressed variation shape mimicry loci in a butterfly adaptive radiation.PLoS Biol 18(2): e3000597. https://doi.org/10.1371/journal.pbio.3000597 Muller, F. (1879). Ituna and Thyridia: a remarkable case of mimicry in butterflies. Transactions of the Entomological Society of London 1879: 20-29. Noonan B.P., Comeault A., A. (2008). The role of predator selection on polymorphic aposematic poison frogs. Biol. Lett.551-54http://doi.org/10.1098/rsbl.2008.0586O'Donald, P., Pilecki, C. (1970). Polymoprhic mimicry and natural selection. Evolution; international journal of organic evolution, 24(2), 395-401. https://doi.org/10.1111/j.1558-5646.1970.tb01770.x Pinheiro, C. E. G. (1996). Palatablility and escaping ability in Neotropical butterflies: Tests with wild kingbirds (Tyrannus melancholicus, Tyrannidae). Biological Journal of the Linnean Society, 59(4), 351-365. https://doi.org/10.1111/j.1095-8312.1996.tb01471.x Pinheiro C. E. G.. (2011). On the evolution of warning coloration, Batesian and Mullerian mimicry in Neotropical butterflies: the role of jacamars (Galbulidae) and tyrant-flycatchers (Tyrannidae). J. Avian Biol. 42, 277-281. http://doi.org/10.1111/j.1600-048X.2011.05435 Roland, A. B., Santos, J. C., Carriker, B. C., Caty, S. N., Tapia, E. E., Coloma, L. A., \& O'Connell, L. A. (2017). Radiation of the polymorphic Little Devil poison frog (Oophaga sylvatica) in Ecuador. Ecology and evolution, 7(22), 9750-9762. https://doi.org/10.1002/ece3.3503 Rosser, N., Dasmahapatra, K.K. and Mallet, J. (2014). StableHeliconius 
butterfly hybrid zones are correlated with a local rainfall peak at the edge of the Amazon basin. Evolution, 68: 3470-3484. http://doi.org/10.1111/evo.12539RStudio Team (2020). RStudio: Integrated Development for R. RStudio, PBC, Boston, MA Saenko S.V., Chouteau M., Piron-Prunier F., Blugeon C., Joron M., Llaurens V. (2019) Unravelling the genes forming the wing pattern supergene in the polymorphic butterfly Heliconius numata.EvoDevo 10, 16 .https://doi.org/10.1186/s13227-019-0129-2Sanders, K.L.; Malhotra, A.; Thorpe, R.S. (May 2006). "Evidence for a Mullerian mimetic radiation in Asian pitvipers". Proceedings. Biological Sciences. 273 (1590): 1135-1141.doi:10.1098/rspb.2005.3418. Seymoure, B. M., Raymundo, A., McGraw, K., Owen Mcmillan, W., \& Rutowski, R. L. (2018). Environment-dependent attack rates of cryptic and aposematic butterflies. Current Zoology, 64(5), 663-669.https://doi.org/10.1093/cz/zox062Sheppard PM. (1963). Some genetic studies of Mullerian mimics in butterflies of the Heliconius genus. Zoologica. 48:145-154. Speed, M.P. and Turner, J.R.G. (1999). Learning and memory in mimicry: II. Do we understand the mimicry spectrum? Biol. J. Linn. Soc. 67, 281+-312. Su, S., Lim, M., \& Kunte, K. (2015). Prey from the eyes of predators: Color discriminability of aposematic and mimetic butterflies from an avian visual perspective. Evolution; international journal of organic evolution, 69(11), 2985-2994. https://doi.org/10.1111/evo.12800 Supple, M. A., Hines, H. M., Dasmahapatra, K. K., Lewis, J. J., Nielsen, D. M., Lavoie, C., Ray, D. A., Salazar, C., McMillan, W. O., \& Counterman, B. A. (2013). Genomic architecture of adaptive color pattern divergence and convergence in Heliconius butterflies. Genome research, 23(8), 1248-1257. https://doi.org/10.1101/gr.150615.112 Symula, R., Schulte R., Summers K., (2001). Molecular phylogenetic evidence for a mimetic radiation in Peruvian poison frogs supports a Mullerian mimicry hypothesis. Proc. R. Soc. Lond. B.2682415-2421http://doi.org/10.1098/rspb.2001.1812Thery M, Pincebourde S, Feer F (2008). Dusk light environment optimizes visual perception of conspecifics in a crepuscular horned beetle. Behav Ecol 19(3):627-634. Turner, J. R. G. (1975). A tale of two butterflies. Natural History 84, 28-37. Tuttle, E. M., Bergland, A. O., Korody, M. L., Brewer, M. S., Newhouse, D. J., Minx, P., Stager, M., Betuel, A., Cheviron, Z. A., Warren, W. C., Gonser, R. A., \& Balakrishnan, C. N. (2016). Divergence and Functional Degradation of a Sex Chromosome-like Supergene. Current biology : CB, 26(3), 344-350. https://doi.org/10.1016/j.cub.2015.11.069 Van Belleghem S.M., Alicea Roman P.A., Carbia Gutierrez H., Counterman B.A., Papa R. (2020). Perfect mimicry between Heliconius butterflies is constrained by genetics and development. Proc. R. Soc. B287: 20201267. http://dx.doi.org/10.1098/rspb.2020.1267 Vorobyev, M., \& Osorio, D. (1998). Receptor noise as a determinant of colour thresholds. Proceedings. Biological sciences, 265(1394), 351-358. https://doi.org/10.1098/rspb.1998.0302 West-Eberhard M. J. (1986). Alternative adaptations, speciation, and phylogeny (A Review). Proceedings of the National Academy of Sciences of the United States of America, 83(5), 1388-1392. https://doi.org/10.1073/pnas.83.5.1388 Wee J.L.Q. \& Monteiro A. (2017). Yellow and the Novel Aposematic Signal, Red, Protect Delias Butterflies from Predators. PLoS ONE12(1): e0168243.https://doi.org/10.1371/journal.pone.0168243Williams P. (2007). The distribution of bumblebee color patterns worldwide: possible significance for thermoregulation, crypsis, and warning mimicry. Biological Journal of the Linnean Society, Volume 92, Issue 1, September 2007, Pages 97-118,https://doi.org/10.1111/j.1095-8312.200\%.00878.xYoung, F.J., Montgomery S.H. (2020). Pollen feeding in Heliconiusbutterflies: the singular evolution of an adaptive suite. Proc. $R$. Soc. B.2872020130420201304http://doi.org/10.1098/rspb.2020.1304

\section{Appendix 1}

\section{Attacked models}




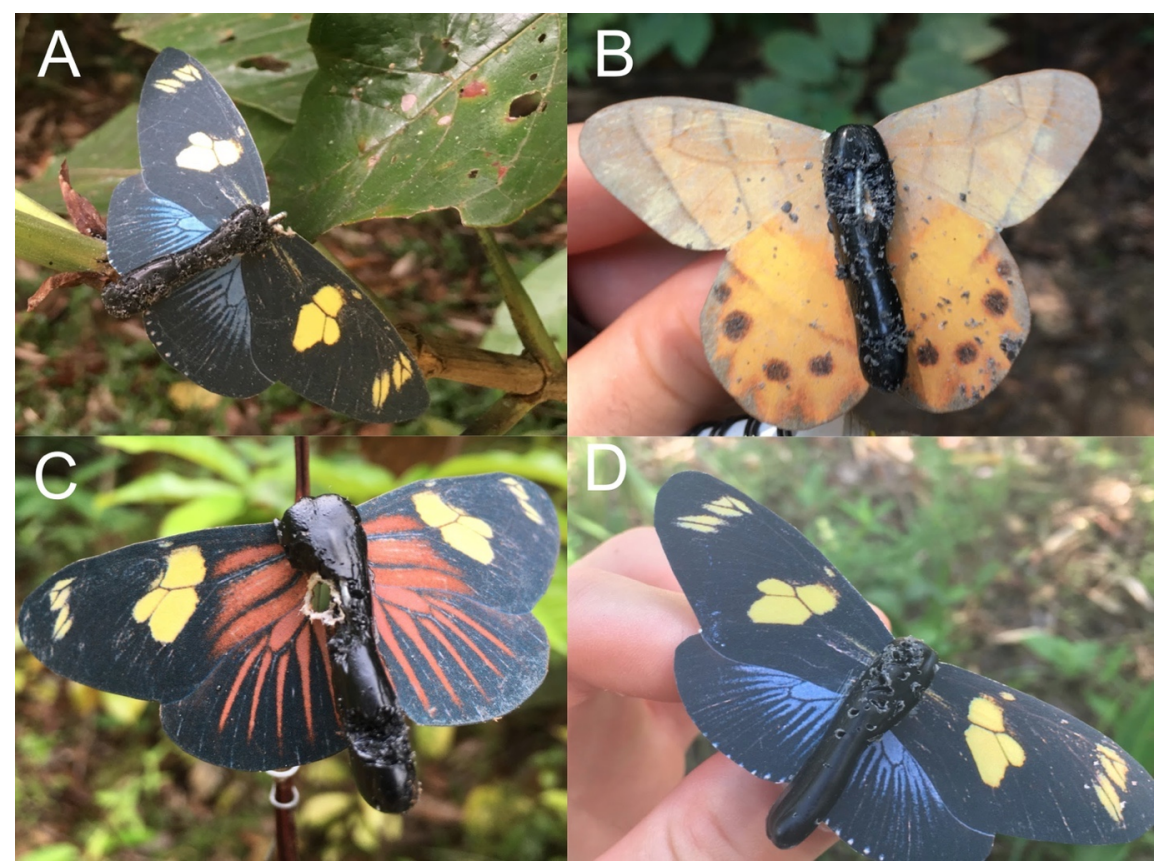

A.Model displaying characteristic invertebrate minute jaw marks distributed throughout the body (common on models placed on cecropia trees which are often inhabited by colonies of azteca ants). B.Unknown vertebrate predator attack (or mixed predators). C.Avian predator attack (damage usually concentrated on anterior or posterior extremities of the main body). D. Avian attack showing peck marks

\section{Figure legends}

Figure 1. Heliconius doris distribution, polymorphic forms and co-mimics. A. Distribution of blue and divergent red morphs compared to widespread blue morph distribution. B.Heliconius doris morphs (top row) with respective co-mimics (below).

Figure 2. No significant attack differences between $\boldsymbol{H}$. doris coexisting morphs. A. Average amount of attacks on local morphs of $H$. doris in Panama and French Guiana. B. Average amount of attacks with standard error on individual models representing local $H$. doris morphs throughout all sites $(\mathrm{n}=6)$. Dashed line separates red morphs corresponding to south and Central America, respectively. Statistical tests were performed with raw attack numbers.

Figure 3. Differences in attacks on native and foreign red morphs. A. Divergent red morphs of H. doris at study sites (Panama and French Guiana). B. Percentage of attacks on native and exotic red phenotypes shows a significantly higher predation on exotic phenotypes in the coastal region of French Guiana and significantly lower predation on native phenotypes in the interior zone, where red co-mimics are abundant $\left({ }^{* 1} \mathrm{p}<0.0365,{ }^{* 2} \mathrm{p}<0.023\right.$, Freeman-Tukey [FT] test). Statistical analyses used raw attack numbers, percentages shown here for clarity. Barplots represent two separate FT tests.

Figure 4. Red morphs attacked less at sites with red mimicry-ring present. A. Locations of study sites and co-mimic distributions in French Guiana. B. Attacks of different H. doris morphs and controls at inland and coastal sites that differ in local mimicry rings show significant protection of red morphs at inland sites where red co-mimics are present $(* p<0.027$, Freeman-Tukey test). Statistical analyses used raw attack numbers, percentages shown here for clarity. Barplots represent two separate FT tests.

\section{Data Accesibility Statement}


Data generated from this study and R-scripts utilized can be accessed at https://github.com/jgo23/ModelsPredation-Data

\section{Competing Interests Statement}

The authors declare no competing interests.

\section{Author Contributions}

BAC, JGO, and MC conceived and designed the study. RP and WOM provided advice on experiential design and support for conducting the experiments. JGO, BAC, MC, RR, and SVB performed the experiments. JGO, MC, SVB, and BAC conducted analyses and wrote the manuscript, with input from all co-authors.

\section{Acknowledgements}

This work was supported by an "Investissement d'Avenir" grant managed by Agence Nationale de la Recherche (CEBA, ref. ANR-10-LABX-25-01) to MC and BAC, an NSF award 1736026 to BAC and RP and the Smithsonian Tropical Research Institute. We thank Neil Rosser for assistance with information on the distributions of $H$. doris. We also thank Melanie McClure for fieldwork assistance in French Guiana and members of the McMillan laboratory for logistical support and discussions on early versions of the manuscript. 